\title{
ANÁLISE ECONÔMICA BASEADA EM FUNÇÕES DE RESPOSTA DA PRODUTIVIDADE VERSUS LÂMINAS DE ÁGUA PARA O MAMOEIRO NO NORTE FLUMINENSE ${ }^{1}$
}

\author{
FREDERICO T. DE ALMEIDA ${ }^{2}$, SALASSIER BERNARDO ${ }^{3}$, ELIAS F. DE SOUSA ${ }^{4}$, \\ SÉRGIO L. D. MARIN ${ }^{5}$, SIDNEY GRIPPA ${ }^{6}$
}

RESUMO: A potencialidade de um pólo de fruticultura irrigada no Norte Fluminense é enorme, dada a região apresentar muitas vantagens. Entretanto, a viabilidade de um sistema de produção dependerá do adequado manejo do mesmo, carecendo de análises econômicas dos insumos aplicados e dos resultados obtidos para estabelecer uma diretriz. Baseado nessas premissas, o objetivo deste trabalho foi avaliar o manejo da água a aplicar por meio de análises econômicas das funções de resposta (água $\mathrm{x}$ produção) e, ainda, considerando os diferentes mercados a atingir, nacional e internacional. Foi montado um experimento com diferentes lâminas de irrigação na cultura do mamão, com a cultivar "Improved Sunrise Solo 72/12", plantada em fileiras duplas, com espaçamento 3,6 x 2,0 x 2,0 m. Foi utilizado um sistema de irrigação por microaspersão com vazão e pressão de $9,7 \times 10^{-3} \mathrm{~L} \mathrm{~s}^{-1}$ e $150 \mathrm{kPa}$, respectivamente. Os níveis de irrigação aplicados foram em função da evapotranspiração de referência $\left(\mathrm{ET}_{0}\right)$, ou seja, $0 ; 40 ; 80 ; 120 ; 160 ; 200$ e $240 \%$ da ETo. Os resultados encontrados, no período de 16 meses, permitiram estimar que as lâminas ótimas econômicas (precipitação + irrigação) foram de 2.818 e $2.832 \mathrm{~mm}$, correspondendo a 45,4 e $35,5 \mathrm{t} \mathrm{ha}^{-1}$ de produtividade do mercado nacional e internacional, respectivamente.

PALAVRAS-CHAVE: análise econômica, manejo de irrigação, mamão.

\section{ECOMOMIC ANALYSIS BASED ON RESPONSE FUNCTION PRODUCTIVITY VERSUS DEPTH WATER OF PAPAYA PLANT IN THE NORTH OF RIO DE JANEIRO STATE, BRAZIL}

SUMMARY: The potentiality of irrigated horticulture pole in the Northern Fluminense is enormous, as the region presents a lot of advantages. However, the viability of the production system will depend on its appropriate management, lacking economical analyses of the applied inputs and results obtained to settle down a guideline. Based on those premises, this work aims to evaluate the appropriate water management to be applied through economical analyses of the answer functions (water x production) and, moreover, considering the different markets to be reached, mainly national and international. An experiment was set up with different irrigation sheets in papaya crop, with "Improved Sunrise Soil $72 / 12$ " cultivar, in double arrays with spacing of $3.6 \times 2.0 \times 2.0 \mathrm{~m}$. A microsprinkler irrigation system was used, with flow and pressure equal to $9.7 \times 10^{-3} \mathrm{~L} \mathrm{~s}^{-1}$ and $150 \mathrm{kPa}$, respectively. The applied irrigation levels, as function of the reference evapotranspiration $\left(\mathrm{ET}_{0}\right)$, were $0 ; 40 ; 80 ; 120 ; 160 ; 200$ and $240 \%$ of $\mathrm{ET}_{0}$. The obtained results, in the period of 16 months, allowed to estimate that the best economical dephts (rain + irrigation) were equal to 2,818 and $2,832 \mathrm{~mm}$, corresponding to 45.4 and $35.5 \mathrm{t} \mathrm{ha}^{-1}$ of the national and international market production, respectively.

KEYWORDS: economic analysis, irrigation management, papaya.

\footnotetext{
${ }^{1}$ Extraído da tese de Doutorado do primeiro autor, em Produção Vegetal, pela Universidade Estadual do Norte Fluminense (UENF), financiada pela Fundação Estadual do Norte Fluminense (FENORTE).

${ }^{2}$ D.Sc. em Produção Vegetal, Professor Associado do Laboratório de Engenharia Civil (LECIV), UENF, Campos dos Goytacazes - RJ, Fone: (0XX24) 2726.1517, e-mail: fredterr@uenf.br

${ }^{3}$ Ph.D. em Irrigação e Drenagem, Prof. Titular do Laboratório de Engenharia Agrícola da UENF.

${ }^{4}$ D.Sc. em Produção Vegetal, Prof. Associado do Laboratório de Engenharia Agrícola da UENF.

${ }_{6}^{5}$ M.Sc. em Fitotecnia, Técnico de Nível Superior do Laboratório de Fitotecnia da UENF.

${ }^{6}$ Técnico Agrícola, Técnico de Nível Médio do Laboratório de Engenharia Agrícola da UENF.

Recebido pelo Conselho Editorial em: 28-8-2001
}

Aprovado pelo Conselho Editorial em: 6-12-2004 


\section{INTRODUÇÃO}

A região Norte-Fluminense passa por um momento peculiar, com a perspectiva de implantação de um pólo de fruticultura irrigada, como forma de mudar o cenário de estagnação em que hoje se encontra, devido à economia alicerçada em anos de exploração da monocultura da cana-de-açúcar e à deficiência na utilização de tecnologias adequadas ao sistema produtivo.

A expectativa pela mudança advém da necessidade de diversificação da economia, mas também de estudos remotos, dos tempos áureos da cana-de-açúcar, por meio de levantamentos hidrológicos e pedológicos de uma determinada área da região Norte-Fluminense, realizado pela SONDOTÉCNICA (1983), que chegou à conclusão da possibilidade de utilização de irrigação para a cultura da cana-deaçúcar em uma área de cerca de 220.000 ha. Baseada nesses estudos, porém com um panorama mais atual, CAMPO (1998), com a intenção da implantação de um Pólo Agroindustrial na região, estimou o aproveitamento dessa mesma área com irrigação, porém sendo 152.000 ha para fruticultura e o restante para a cana-de-açúcar. Foram também desenvolvidos estudos de mercado e seu potencial para dez anos, tanto para o mercado nacional como para o internacional e, ainda, estudos de viabilidade econômica de módulos de fruticultura, apresentando taxas de retorno, "payback" e outros.

Nesse contexto, pode-se destacar a potencialidade do plantio de mamão nessa região, pois apresenta vantagens, como condições edafoclimáticas propícias, disponibilidade hídrica razoável, mãode-obra abundante, infra-estrutura estadual para exportação, além da viabilidade econômica, devido à proximidade de um grande mercado consumidor interno (Rio de Janeiro), perspectivas de aumento da exportação, altas taxas de crescimento de consumo (25 a $30 \%$ ao ano), além do rápido retorno econômico da cultura.

Os estudos citados potencializam a viabilidade econômica dos sistemas de produção, baseados em estimativas de mercado e parâmetros econômicos das culturas, entretanto não definem o manejo a ser aplicado para obter a maximização do retorno financeiro dessas, carecendo de análises econômicas de pesquisas aplicadas.

Apesar de a grande maioria das lavouras comerciais de mamão serem irrigadas, pouco se sabe sobre a demanda de água da cultura e seu efeito na produtividade, como exemplo dos trabalhos de: SILVA (1999), em que se estudou a interação de várias freqüências e várias lâminas de irrigação (até $120 \%$ ETo) sobre a produção, tendo essa porcentagem apresentado a maior produtividade; AWADA et al. (1979), que estudaram a aplicação de cinco lâminas de irrigação (de 33 a 162\% ETo), encontrando a maior produtividade para a reposição de $129 \%$ ETo. Esses fatos demonstram a necessidade de pesquisas para recomendar aos produtores corretas alternativas para o manejo da irrigação na cultura.

Como forma de viabilizar um sistema de produção ou para aumentar a sua rentabilidade, a utilização de sistemas de irrigação nem sempre atinge seu objetivo, devido, muitas vezes, à falta de dados que demonstrem se o acréscimo de produção compensará o custo desse pacote tecnológico. Assim, estudos com enfoque econômico, que levem em conta a resposta da produção da cultura em relação a diferentes lâminas de irrigação, são fundamentais para viabilizar e difundir a exploração da cultura em uma região (FRIZZONE, 1993; BERNARDO, 1998).

Outro fator a destacar é que existe distinção na qualidade dos frutos de mamão demandados pelos mercados externo e interno, bem como da rentabilidade, com a oferta de melhores preços pelo mercado internacional, estáveis, em torno de $0,27 \mathrm{US} \mathrm{kg}^{-1}$ de fruto, contra preços com média mensal variando de 0,12 a 0,34 US\$ $\mathrm{kg}^{-1}$ de fruto para o mercado nacional (MARIN \& SILVA, 1996). Isso demonstra que o manejo dos insumos o qual se deve implementar ao sistema produtivo, dependerá do mercado que se quer atingir, de forma a permitir uma otimização dos insumos aplicados.

Sendo assim, o objetivo deste trabalho foi avaliar o adequado manejo da água a aplicar, por meio de análise econômica das funções de resposta da produtividade em relação à lâmina total de água 
aplicada, ajustando as outras variáveis e/ou insumos para produtividades máximas e considerando os diferentes mercados que se quer alcançar, nacional e/ou internacional.

\section{MATERIAL E MÉTODOS}

O experimento foi realizado na Fazenda Experimental da Empresa de Pesquisa Agropecuária do Estado do Rio de Janeiro, em Campos dos Goytacazes, Região Norte do Estado do Rio de Janeiro.

Foi estudada a cultivar do grupo Solo "Improved Sunrise Solo 72/12", plantada com espaçamento de 3,6 x 2,0 x 2,0 m (3,6 m entre fileiras duplas, 2,0 m entre fileiras simples e 2,0 m entre plantas numa fileira). O experimento foi em blocos casualizados, com sete tratamentos (lâminas de irrigação) e três repetições; cada parcela teve 12 plantas, sendo cinco plantas consideradas úteis. Foi utilizado um sistema de irrigação por microaspersão, sendo um microaspersor para cada quatro plantas, com vazão de $9,7 \times 10^{-3} \mathrm{~L} \mathrm{~s}^{-1}$, pressão de $150 \mathrm{kPa}$, raio de molhamento de 2,0 m e porcentagem de área molhada da cultura de $56 \%$. Os níveis de irrigação aplicados foram em função da evapotranspiração de referência $\left(\mathrm{ET}_{0}\right)$, ou seja, $0 ; 40 ; 80 ; 120 ; 160 ; 200$ e $240 \%$ da ETo, valores esses adotados para se obter uma curva de rendimentos com crescimento e decréscimo. Os volumes de água aplicados, três vezes por semana, foram controlados por hidrômetros instalados em cada tratamento.

A adubação foi baseada na análise de solo e de acordo com recomendação para altas produtividades (MARIN et al., 1995). Foram realizadas vistorias constantes na cultura para controle de plantas daninhas, de pragas e doenças utilizando os defensivos necessários.

Os dados climáticos necessários para fazer o balanço hídrico, como precipitação e evaporação no tanque "Classe A", foram coletados no local do experimento, onde há uma estação meteorológica.

Para os dados de produção, individualizados por planta, por motivo de perdas com virose, a colheita foi feita semanalmente, obtendo-se as médias por parcela.

A função de produção foi obtida por meio de análise de regressão, entre a produtividade e os níveis de água aplicados, ajustada por um modelo polinomial de segunda ordem (HEXEM \& HEADY, 1978; FRIZZONE, 1993), sendo:

$$
\mathrm{P}=\mathrm{P}(\mathrm{A})=\mathrm{a}+\mathrm{b} \mathrm{A}+\mathrm{c} \mathrm{A}^{2}+\mathrm{ei}
$$

em que,

$\mathrm{P}$ - produtividade, $\mathrm{t} \mathrm{ha}^{-1}$

A - lâmina total de água aplicada (irrigação + precipitação), mm;

a, b e c - parâmetros de ajuste, adimensional, e

ei - erro aleatório.

Com a função ajustada, foi determinado o nível de água (Am) que maximizou a produção.

$$
\mathrm{Am}=-\frac{\mathrm{b}}{2 \mathrm{c}}
$$

O lucro da produção foi obtido com a diferença entre o valor monetário total da produção e dos custos da aplicação de água e do fixo do sistema produtivo, incluindo o sistema de irrigação.

$$
\mathrm{LP}=\mathrm{LP}(\mathrm{A})=\mathrm{P}_{\mathrm{P}} \mathrm{P}(\mathrm{A})-\left(\mathrm{P}_{\mathrm{A}} \mathrm{A}+\mathrm{C}\right)+\mathrm{ei}
$$

em que,

LP - lucro da produção ou receita líquida obtida, $\mathrm{R}$;

$\mathrm{P}_{\mathrm{P}}$ - preço do produto, $\mathrm{R} \$ \mathrm{~kg}^{-1}$;

$\mathrm{P}_{\mathrm{A}}$ - preço da água, $\mathrm{R} \$ \mathrm{~m}^{-3}$, e

$\mathrm{C}$ - custo fixo, $\mathrm{R} \$ \mathrm{ha}^{-1}$. 
A maximização do lucro foi obtida calculando-se a derivada de primeira ordem da eq.(3) em relação a $A$ e igualando a zero, obtendo-se a equação da lâmina ótima $\left(\mathrm{A}_{\mathrm{ot}}\right)$ que maximizou a receita:

$$
\mathrm{A}_{\mathrm{ot}}=\frac{\mathrm{P}_{\mathrm{A}}-\mathrm{P}_{\mathrm{P}} \mathrm{b}}{2 \mathrm{P}_{\mathrm{P}} \mathrm{c}}
$$

Esses procedimentos foram realizados para a produção, visando aos mercados nacional e internacional, sendo os frutos com peso de 280 a 890 g e de 290 a 650 g, respectivamente, conforme recomendações de MARIN \& SILVA (1996).

Os autores verificaram que o preço médio do fruto de mamão era de $0,17 \mathrm{US}_{\mathrm{kg}}^{-1}$ e de

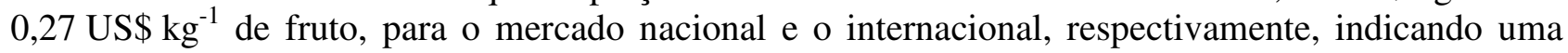
diferença de $159 \%$ entre os dois mercados. Esses dados foram gerados pelo levantamento realizado pelos autores, em que analisaram o comportamento de preços do mamoeiro do grupo "Solo", recebido pelo produtor, na região Norte do Espírito Santo, no período de 1990 a 1995, considerando os diferentes mercados consumidores e médias mensais ponderadas, devido à pequena oferta do produto no inverno e maior oferta no restante do ano.

Todavia, considerando-se os preços vigentes na época, o preço médio de mamão observado no ano de 1999 foi de 0,107 US\$ kg ${ }^{-1}$ de fruto (AGRIANUAL, 2000); portanto, adotou-se, neste trabalho, para efeito de estudos, o preço médio do fruto de mamão de $0,107 \mathrm{US} \mathrm{kg}^{-1}$ para o mercado nacional e estimou-se de 0,170 US $\$ \mathrm{~kg}^{-1}$ de fruto para o mercado internacional (diferença citada anteriormente).

Para o custo da lâmina de água, em $\mathrm{R} \$ \mathrm{~m}^{-3}$, foram considerados dados médios do experimento, utilizando-se da metodologia do cálculo do custo da energia para irrigação (CARVALHO et al., 1996).

O custo fixo do sistema produtivo, incluindo o sistema de irrigação, com depreciação para vida

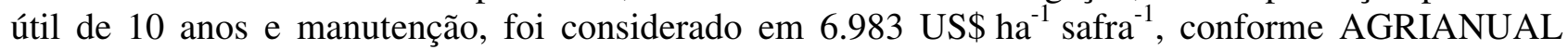
(2000).

Foi realizada, também, uma análise da eficiência do uso da água, em $\mathrm{kg} \mathrm{m}^{-3}$, utilizando-se dos dados das lâminas totais de água e a produção comercial obtida para cada mercado, com posterior determinação de uma função de produção da água x eficiência de uso de água.

\section{RESULTADOS E DISCUSSÃO}

Os dados climáticos obtidos com a evapotranspiração total de $1.632 \mathrm{~mm}$ (determinada pelo Tanque Classe A) e da precipitação total de $1.188 \mathrm{~mm}$ indicam a necessidade de irrigação para a região em questão, sem contar que, fazendo-se o balanço mensal, se verifica que existem períodos em que a precipitação supera a demanda evapotranspirométrica, indicando a diminuição ainda maior da chuva efetiva, como proporção da chuva total (Tabela 1). Entretanto, a quantidade de água que se deve aplicar para obter a máxima rentabilidade, necessita de análises econômicas.

TABELA 1. Resumo dos dados climáticos mensais, precipitação total (Prec.) e evapotranspiração de referência (ETo), no período do experimento.

\begin{tabular}{ccccccccccccccccccc}
\hline Mês & ago. & set. & out. & nov. & dez. & jan. & fev. & mar. & abr. & maio & jun. & jul. & ago. & set. & out. & nov. & dez. & Total \\
& 98 & 98 & 98 & 98 & 98 & 99 & 99 & 99 & 99 & 99 & 99 & 99 & 99 & 99 & 99 & 99 & 99 & \\
\hline $\begin{array}{l}\text { Prec. } \\
\text { (mm) }\end{array}$ & 23 & 16 & 125 & 15 & 147 & 14 & 16 & 137 & 33 & 32 & 37 & 25 & 22 & 39 & 86 & 210 & 69 & 1.188 \\
$\begin{array}{c}\text { ETo } \\
(\mathrm{mm})\end{array}$ & 57 & 99 & 87 & 91 & 131 & 153 & 164 & 155 & 93 & 78 & 57 & 64 & 84 & 112 & 103 & 87 & 17 & 1.632 \\
\hline
\end{tabular}


Os dados de produção, determinados em função das diferentes lâminas totais de água aplicadas (precipitação + irrigação), considerando os dois mercados-alvo estabelecidos, ajustaram-se em polinômios de segundo grau, significativos a $1 \%$ de probabilidade, com elevados coeficientes de determinação para a produtividade comercial destinada ao mercado nacional (Pcn) e ao mercado internacional (Pci) (Figura 1).

Quando não se consegue obter o comportamento de aumento e decréscimo da produtividade com o crescente incremento de lâminas de água, é porque a máxima aplicação de água não é suficiente para fornecer condições potenciais de produção e, conseqüentemente, não se consegue estabelecer condições ótimas econômicas. Todavia, com níveis elevados de aplicação de água, obtêm-se resultados que permitem essas análises econômicas, como se verificou no trabalho realizado nesta mesma região, com a cultura da cana-de-açúcar e da goiaba (SOUSA, 1997).

Apesar de o comportamento de aumento e decréscimo da produtividade ser esperado nas respostas das produtividades das culturas à crescente aplicação de água, principalmente na cultura do mamão, devido à sensibilidade ao encharcamento do solo, vários autores, estudando esse mesmo efeito, não aplicaram lâminas suficientemente grandes, de forma que obtivessem decréscimo na produção (SRINIVAS, 1996; SILVA, 1999), exceto AWADA et al. (1979).

Esse fato é indicativo de que a maioria dos estudos não chegaram a determinar a taxa de reposição de água que obtivesse a máxima produção.

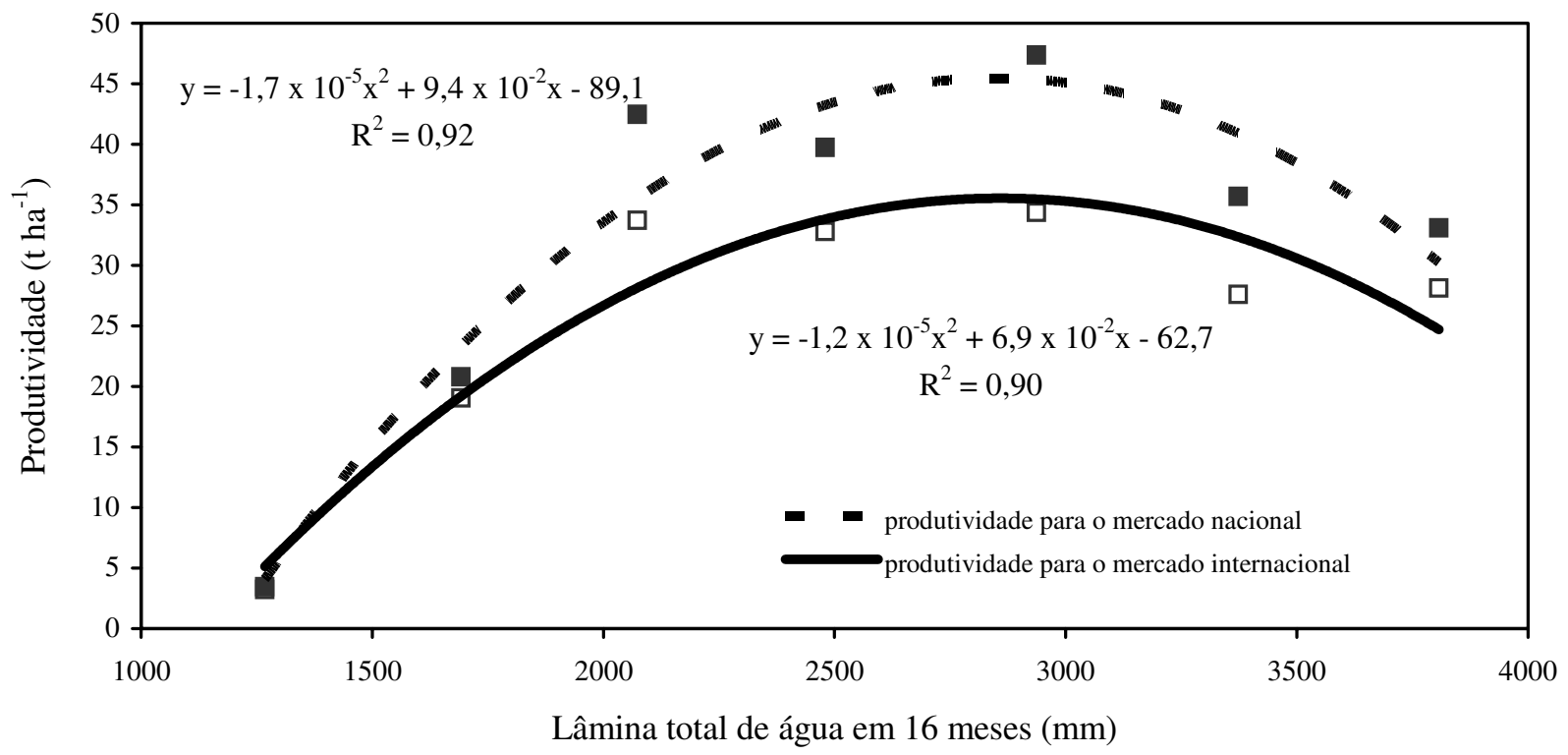

FIGURA 1. Estimativa da produtividade comercial para o mercado nacional e para o mercado internacional, em função das lâminas totais de água aplicadas (irrigação + precipitação).

A produtividade comercial máxima estimada foi de $45,4 \mathrm{t} \mathrm{ha}^{-1}$ de frutos entre 280 e $890 \mathrm{~g}$ (para o mercado nacional) e de $35,5 \mathrm{tha}^{-1}$ de frutos entre 290 e $650 \mathrm{~g}$ (para o mercado internacional), respectivamente, com as lâminas totais de água aplicadas de 2.847 e $2.858 \mathrm{~mm}$.

Como a máxima produtividade, nem sempre, corresponde à melhor rentabilidade a ser obtida, torna-se necessária a avaliação dos custos para identificar em que ponto o incremento de água e, conseqüentemente, de produção, deixa de gerar maiores lucros. 
Considerando um módulo de 1 ha da cultura, com um motor trifásico de $2 \mathrm{cv}$, o consumo é de $1,96 \mathrm{kWh} \mathrm{h}^{-1}$ (CARVALHO et al., 1996), e com o custo da energia elétrica de $0,213 \mathrm{R} \$ \mathrm{kWh}^{-1}$ (CERJ, 2000), gasta-se $0,42 \mathrm{R} \$ \mathrm{~h}^{-1} \mathrm{ha}^{-1}$.

A cultura do mamão, quando totalmente estabelecida, apresenta o fator porcentagem de área molhada de aproximadamente 56\% (OLITTA, 1986; PIZARRO CABELO, 1990), e com o microaspersor molhando quatro plantas, com uma área total das plantas de $22,4 \mathrm{~m}^{2}$, a intensidade de aplicação de água do microaspersor é de $2,78 \mathrm{~mm} \mathrm{~h}^{-1}$.

Com esses dados estabelecidos, o custo variável referente à energia gasta na aplicação de água é de $0,0151 \mathrm{R} \$ \mathrm{~m}^{-3}$ ou $0,0151 \mathrm{R} \$ \mathrm{~mm}^{-1} \mathrm{ha}^{-1}$.

Considerando-se a taxa cambial média no ano de 1999, com US\$1,00 sendo equivalente a $\mathrm{R} \$ 1,81$, o preço do mamão seria de 0,194 e de $0,308 \mathrm{R} \mathrm{kg}^{-1}$ de fruto, respectivamente, para os frutos destinados ao mercado nacional e ao internacional. Com o custo de aplicação da água de $0,0151 \mathrm{R} \$ \mathrm{~m}^{-3}$, estimaram-se as lâminas ótimas econômicas, $2.824 \mathrm{~mm}$ para produção destinada ao mercado nacional e $2.837 \mathrm{~mm}$ para o internacional, correspondendo a produtividades ótimas de 45,4 e $35,5 \mathrm{t} \mathrm{ha}^{-1}$, respectivamente.

Apesar de as lâminas estimadas, com que se obtém ótimo retorno econômico, serem pouco menores que as estimadas para a máxima produção, tanto para o mercado nacional quanto o internacional, a produtividade encontrada para ambos os mercados e nos dois casos são iguais, podendo-se dizer que a máxima produção é a que fornece maior rentabilidade econômica, fato também observado para a cultura da cana-de-açúcar e da goiabeira por SOUSA (1997).

Esses resultados indicam que os incrementos de produtividade com aumento da lâmina aplicada, até o ponto de máxima produção, são suficientemente grandes para cobrir o custo de aplicação da água, ou melhor, devido ao custo de implantação da cultura ser muito elevado, o modelo em questão torna-se pouco sensível ao custo de aplicação da água, porque a água, enquanto insumo natural, tem custo zero.

Outro fato interessante verificado foi a proximidade das lâminas ótimas estimadas para a produção comercial destinada ao mercado nacional e ao mercado internacional, indicando que o mesmo manejo da irrigação deve ser dado a esta cultura, não importando o mercado a que se destina.

Essa discussão faz sentido porque os tratamentos com lâminas aplicadas, em torno da lâmina de máxima produção (T3, T4, T5 e T6), e destacadamente no ponto ótimo de irrigação, produziam maior número de frutos e principalmente frutos grandes. Como a produção destinada ao mercado mundial exclui certa quantidade de frutos pesados, diminuindo assim a sua produtividade, como se verificou, isso poderia interferir na lâmina ótima econômica.

Ocorreu a coincidência das lâminas ótimas de água devido ao diferencial de preços em cada mercado, apesar de as produtividades estimadas serem diferentes para cada um. Todavia, a rentabilidade pode não ter o mesmo raciocínio acima.

O custeio da cultura do mamão foi estimado em 6.983,00 US\$ ha ${ }^{-1}$ por safra, ou em três anos (AGRIANUAL, 2000). Todavia, neste trabalho, obtiveram-se as produtividades apresentadas num período total de 16 meses, desde o plantio e, considerando-se que a distribuição do custo não é linear, estabeleceu-se a metade do custo fixo total (AGRIANUAL, 2000) que, nesse caso, é de 3.492,00 US $\$ \mathrm{ha}^{-1}$, e sendo US\$ 1,00 equivalente a R \$ 1,81, o custo fixo, incluindo o sistema de irrigação, seria de $6.320,00 \mathrm{R} \$ \mathrm{ha}^{-1}$, para efeito de análise.

Dessa forma, a rentabilidade apresentada pela produção destinada aos diferentes mercados, estimada em função da lâmina total ótima econômica de água e para o período considerado, foi de $1.953,00$ e de 4.086,00 $\mathrm{R} \$ \mathrm{ha}^{-1}$, nessa ordem, para o mercado nacional e para o internacional, 
visualizando que, apesar da menor produtividade para o mercado internacional, o maior preço do produto tende a compensar a receita.

Ainda na tentativa de estimar uma receita anual e, para isso, considerando que a receita obtida com os dados do período deste trabalho (16 meses) se aproxima da metade da que se obteria com a safra inteira (três anos), ter-se-ia 1.369,33 e 2.792,00 $\mathrm{R} \$$ ha $^{-1} \mathrm{ano}^{-1}$ para os mercados nacional e internacional, respectivamente. Vale ressaltar que a produção excedente não-comercializável (de frutos com mais de $650 \mathrm{~g}$ ) no mercado internacional poderia ser aproveitada para o mercado interno, gerando receitas ainda maiores.

Enfim, pode-se perceber que a análise econômica permite estabelecer o manejo de irrigação mais adequado para a cultura do mamão, como também mostra a necessidade da irrigação, pois o tratamento sem irrigação apresentou rentabilidades negativas para ambas as análises de mercado.

Outra importante relação que se determinou foi entre a eficiência do uso de água e as lâminas totais de água aplicadas (precipitação + irrigação), pois permite conhecer como a planta, ou o sistema em questão, está utilizando a água no processo de transformação em produto comercializável (OLIVEIRA, 1993).

Ajustaram-se polinômios de segundo grau, significativos a $1 \%$ de probabilidade, para os dados de eficiência de uso de água em função das diferentes lâminas totais de água aplicadas, obtendo-se excelentes coeficientes de determinação para as eficiências do uso de água para a produção comercial para o mercado nacional (EUAcn) e para o mercado internacional (EUAci) (Figura 2).

As lâminas que obtiveram a máxima eficiência no uso de água para cada análise de mercado considerada foram de 2.584 e de $2.553 \mathrm{~mm}$, correspondendo a 1,8 e 1,3 $\mathrm{kg} \mathrm{m}^{-3}$, para as EUAcn e EUAci, respectivamente.

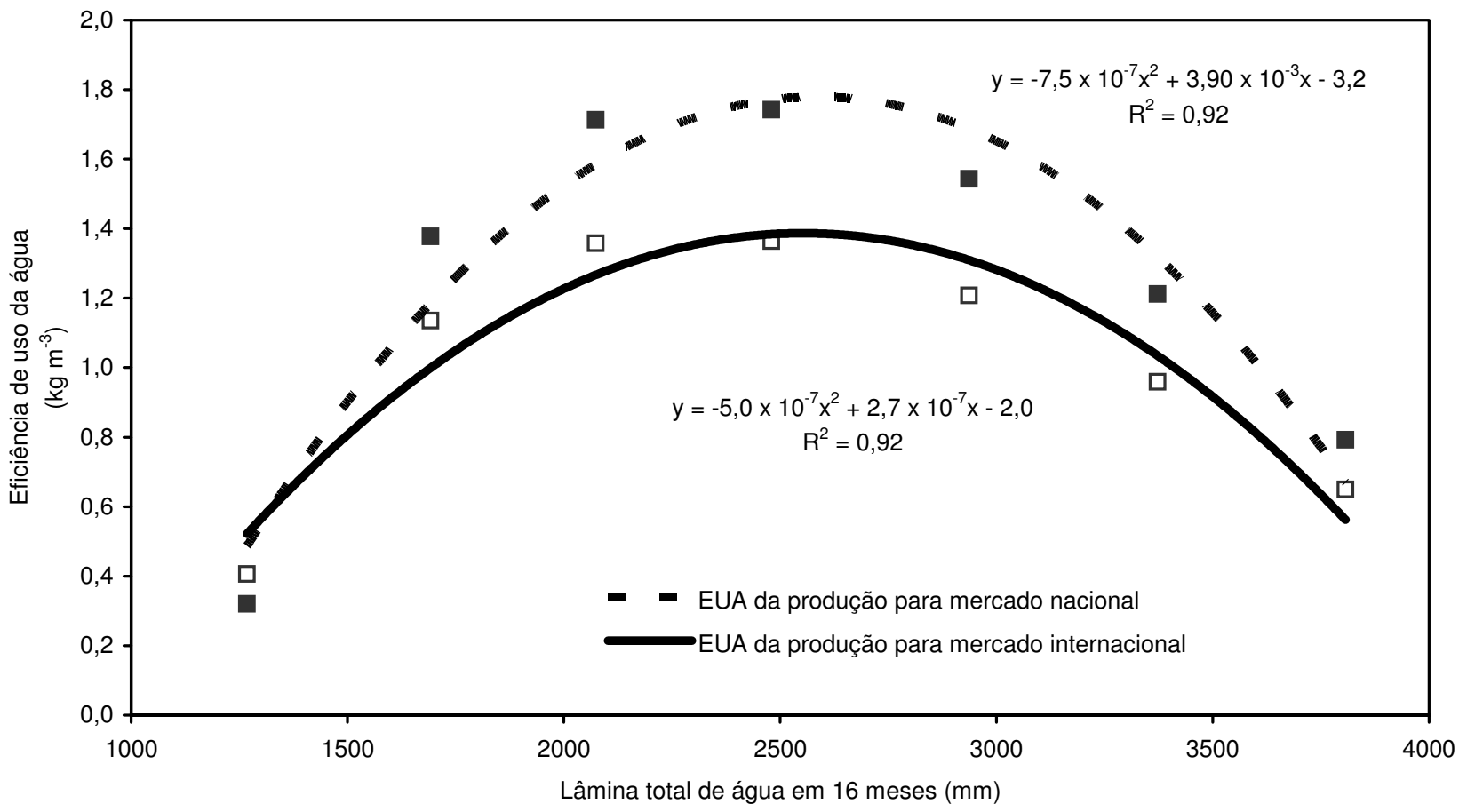

FIGURA 2. Estimativa da eficiência do uso de água pela cultura de mamão, para os mercados nacional e internacional, em função das lâminas totais aplicadas (irrigação + precipitação). 
Para efeito comparativo, determinaram-se, também, as eficiências de uso de água para a máxima produção e a produção ótima econômica, que foram ambas de $1,7 \mathrm{~kg} \mathrm{~m}^{-3}$, para a produção nacional e ambas de $1,3 \mathrm{~kg} \mathrm{~m}^{-3}$, para a produção internacional.

Novamente, verifica-se o destaque da produção para o mercado nacional no uso eficiente da água, sendo os valores da EUAcn maiores que os da EUAci, haja vista a discussão anterior de que o aumento das lâminas de irrigação levavam à produção de frutos maiores que não eram considerados na produção para o mercado internacional e por isso diminuindo o uso eficiente da água.

Esses resultados demonstram que as lâminas que têm a máxima eficiência de uso de água, não coincidem com as lâminas que apresentam máxima produção ou produção ótima econômica, não sendo significativo para o presente estudo porque a água não é um fator limitante nem é cobrada por sua utilização, mas que será importante em futuro breve, com a escassez e cobrança pelo uso da água.

Outro fato que vale a pena lembrar, é que não foram realizadas medições de escoamento superficial ou percolação profunda da água, não sendo possível estimar as perdas de água. Assim, é importante salientar que as lâminas totais de máxima produção, de máxima eficiência econômica e de máxima eficiência no uso da água podem estar superestimadas em relação à total efetiva necessária para cada caso (aproveitamento da água aplicada com $100 \%$ de eficiência), mas que foram as necessárias a se aplicar devido às condições climáticas apresentadas durante a realização do experimento.

\section{CONCLUSÕES}

As lâminas máximas totais de água (precipitação + irrigação) de 2.847 e $2.858 \mathrm{~mm}$ e as lâminas ótimas econômicas totais de água (precipitação + irrigação) de 2.824 e $2.837 \mathrm{~mm}$, ambas, respectivamente, para os mercados nacional e internacional, apresentaram produtividades iguais para cada mercado, de 45,4 para o nacional e 35,5 $\mathrm{t} \mathrm{ha}^{-1}$ para o internacional.

A proximidade entre as lâminas estimadas, em que se obteve máxima produção e produção ótima econômica, para ambos os mercados, pressupõe a adoção do mesmo manejo de irrigação para a cultura do mamão, independentemente do mercado a que se destina a produção.

O incremento da aplicação das lâminas (precipitação + irrigação) aumenta não só a produção de frutos como também o seu peso, interferindo na eficiência do uso da água (EUA), de acordo com o mercado a que se destina a produção.

As lâminas (precipitação + irrigação) que obtiveram a máxima eficiência no uso de água (EUA), para cada análise de mercado considerada, foram diferentes das EUAs das lâminas que forneceram produtividade máxima e produtividade ótima econômica.

Com as devidas considerações, realizadas neste trabalho, verificou-se que a rentabilidade em função da lâmina total ótima econômica foi de 2.054,00 e de 4.188,00 R $\$ \mathrm{ha}^{-1}$, nessa ordem, para os mercados nacional e internacional.

\section{REFERÊNCIAS}

AGRIANUAL: anuário estatístico da agricultura brasileira. Mamão. São Paulo: FNP - Consultoria e Comércio, 2000. p.374-84.

AWADA, M.; WU, I. P.; SUEHISA, R.H.; PADGETT, M.M. Effects of drip irrigation and fertilization on vegetative growth, fruit yield, and mineral composition of the petioles and fruits of papaya. Honolulu: Hawaii Agricultural Experiment Station, University of Hawaii, 1979. 20 p. (Boletim Técnico, 103). 
BERNARDO, S. Irrigação e produtividade. In: FARIA, M.A.; SILVA, E.L.; VILELA, L.A.A.; SILVA, A.M. (Ed.) Manejo de irrigação. Poços de Caldas: SBEA-UFLA, 1998. p.117-30.

CAMPO - Companhia de Promoção Agrícola. Estudo de viabilidade de um polo agroindustrial para a região Norte-Fluminense. Campos dos Goytacazes: FIRJAN/CIRJ/SESI/SENAI/IEL, 1998. 251 p.

CARVALHO, J.A.; BERNARDO, S.; SOUSA, E.F. Cálculo do custo de energia para irrigação. Campos dos Goytacazes: UENF, 1996. 13 p. (Boletim Técnico, 1 (6)).

CERJ - COMPANHIA DE ELETRIFICAÇÃO DO ESTADO DO RIO DE JANEIRO. Preço de tarifas. Campos dos Goytacazes, 2000. Disponível em: <http://www.cerj.com.br/tarifas.html>. Acesso em: 15 ago. 2000.

FRIZZONE, J. A. Funções de resposta das culturas à irrigação. Piracicaba: EDUSP, 1993. 42 p. (Série Didática, 006).

HEXEM, R.W.; HEADY, E.O. Water production functions for irrigated agriculture. Iowa: The Iowa State University Press, 1978. 215 p.

MARIN, S.L.D.; GOMES, J.A.; SALGADO, J.S.; MARTINS, D.S.; FULLIN, E.A. Recomendações para a cultura do mamoeiro dos grupos Solo e Formosa no Estado do Espírito Santo. 4.ed. Vitória: EMCAPA, 1995. 57 p. (Circular Técnica, 3)

MARIN, S.L.D.; SILVA, J.G.F. Aspectos econômicos e mercados para a cultura do mamoeiro do grupo Solo na região Norte do Espírito Santo. In: MENDES, L.G.; DANTAS, J.L.L.; MORALES, C.F.G. (Eds.) Mamão no Brasil. Cruz das Almas: EMBRAPA-CNPMF, 1996. p.7-20.

OLITTA, A.F.L. Elaboração de projetos de irrigação. Brasília: PNI/FUNDAÇÃO CTH, 1986. 11 p.

OLIVEIRA, S.L. Funções de resposta do milho-doce ao uso de irrigação e nitrogênio. 1993. $91 \mathrm{f}$. Tese (Doutorado em Recursos Hídricos) - Departamento de Engenharia Agrícola, Universidade Federal de Viçosa, Viçosa - MG, 1993.

SILVA, J.G.F. Efeitos de diferentes lâminas e freqüências de irrigação sobre o desenvolvimento e a produtividade do mamoeiro (Carica Papaya L.). 1999. 90 f. Tese (Doutorado em Recursos Hídricos) Departamento de Engenharia Agrícola, Universidade Federal de Viçosa, Viçosa - MG, 1999.

SONDOTÉCNICA. Estudos de levantamentos pedológicos e hidrológicos. In: Projeto de irrigação e drenagem da cana-de-açúcar na região Norte-Fluminense. Rio de Janeiro, 1983. 534 p.

SOUSA, E.F. Função de produção da cana-de-açúcar e da goiabeira em relação à irrigação. 1997. 119 f. Tese (Doutorado em Produção Vegetal) - Universidade Estadual do Norte Fluminense, Campos dos Goytacazes, 1997.

SRINIVAS, K. Plant water relations, yield, and water use of papaya (Carica papaya L.) at different evaporation-replenishment rates under drip irrigation. Tropical Agriculture, Trinidad, v.73, n.4, p.2649, 1996. 